\title{
POSTER
}

\section{Work and Leisure}

H.M. HUA, T.S. SHEU, Y.R. WU. Innovation university interdisciplinary courses design and care service of older adults. Gerontechnology 2018;17(Suppl):198s; https://doi.org/10.4017/gt.2018.17.s.193.00 Purpose Foreseeing aging population issues, Nan Kai University of Technology has set Gerontechnology and service management as one of the key university characteristics of development since 2006. Relative Gerontechnology courses have been arranged under four colleges. Since 2017, the Ministration of Education in Taiwan started the University of Social Responsibility Project (USR), which has helped community development under the concept of localization and social responsibility ${ }^{1,2}$. To serve the aging population with the USR project has become a very important approach for the Nan Kai faculty (Figure 1). Methods An innovation course, 'Introduction of Assistive Technology', was designed for 122 second year Human Ecology students at Nan Kai University. Throughout the semester, the students learned about Assistive Technology for older adults. At the end of the semester, 100 older adults from two communities near Nan Kai were invited to the university to experience ten different types of assistive technology, including wheelchairs, crutches, tableware, memory games, virtual reality games, augmented reality games, iPad games, etc. The evaluation standards of the students' final exam was based not only on their knowledge regarding assistive technology but also their individual performance to serve older adults (Figure 2). Results \& Discussion The 100 older adults from the two communities expressed their gratitude for the opportunity and experience to come to the university and learn about assistive technology. From this project, the students were able to learn how to approach older adults and complete assistive technology services not only in a classroom setting, but also in practical applications of interpersonal connections. This module has proven to be successful for the College of Human Ecology and has the potential to work well for other colleges and universities.

\section{References}

1. Chen WS, Chiou WF. Indigenous Tribal Governance and University Participation: A Case Study of the National Chi Nan University's Participation in the Baike Tribe (Chinese ed.). Journal of The Taiwan Indigenous Studies Association 2017; 7(1): 1-26

2. Hou CH. Effect of Incorporating Service Learning into Social Studies Curriculum on Students' Aging Knowledge, Attitude and Service Intention. Journal of Gerontechnology and Service Management 2017;5(2):133-146

Keywords: innovation university course design, USR, older adults experience design Address: Nan Kai University of Technology, Taiwan;

E: tinahmh@gmail.com

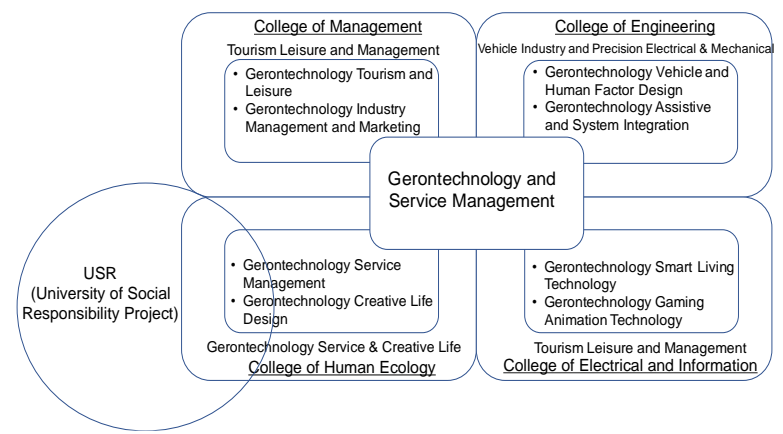

Figure 1. Concept of Innovation university interdisciplinary courses design with USR

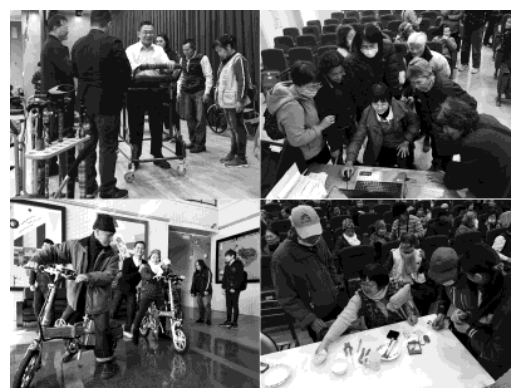

Figure 2. 122 Nan Kai University students helped 100 older adults to experience assistive technology 